\title{
Laboratory Studies on Spinosyns Compounds Against Different Pests
}

\author{
Rania A. Abd El-Wahab", E. M. Anwar, and M. A. El-Gindy \\ Pant Protection Research Institute, Dokki, Giza, Egypt, "E-mail: rppri@aol.com
}

\begin{abstract}
Spinosyns are new neurotoxins mixtures produced during fermentation of a soil actinomycete that have high activity towards different pests. Spinosyns compounds were represented in Spinosad and its evoluted compound ,Spinetoram ,which were tested for their toxic effects under laboratory conditions against adult females of Aphis gossypii Glover and Tetranychus urticae Koch ,and the fourth instar larvae of Spodoptera littoralis (Boisd.)by leaf-dip technique. Spinosad LC50's of A. gossypii, T. urticae and S. littoralis were 30.417,25.982 and 5.379 ppm, respectively but they were $0.596,0.370$ and $1.742 \mathrm{ppm}$,respectively in case of Spinetoram.The superior Spinosyn compounds,Spinetoram gained the best results against piercing-sucking pests compared with Spinosad which was the best against $S$. littoralis ,so the present histological studies were concerned with Spinetoram.Each pest was treated with its LC50 value. Histological defects after treatments in the neuromuscular nicotinic receptors were detected and discussed.
\end{abstract}

Key Words: Spinosyns, Spinosad, Spinetoram, Tetranychus urticae, Aphis gossypii, Spodoptera littoralis.

\section{INTRODUCTION}

Spinosyn and its analogs, produced by Saccharopolyspora spinosa (Mertz and Yao, 1990; Kirst et al., 1991), are the active ingredients in a family of insect control agents. They are macrolides with a 21-carbon, 12-membered tetracyclic lactones that are attached to two deoxysugars, tri-Omethylrhamnose and forosamine. Labeling studies, analysis of the biosynthetically blocked mutants, and the genetic identification of the spinosyn gene cluster have provided detailed information concerning the mechanism of spinosyn biosynthesis and have enabled combinatorial biosynthesis of a large group of new spinosyns. A second-generation spinosyn called spinetoram (XDE-175) was launched in late 2007. It is a semisynthesized spinosyn derivative produced through the modification of 3'-O-methyl group of rhamnose and the double bond between $\mathrm{C} 5$ and $\mathrm{C} 6$ of spinosyn $\mathrm{J}$ and L. This molecule was shown to have improved insecticidal activity, enhanced duration of control, and expanded pest spectrum (Huang et al., 2009).

Mode of action Nicotinic acetylcholine receptors (nAChRs) are major excitatory neurotransmitter receptors in invertebrates. In insects, nAChRs are the target site for several naturally occurring and synthetic compounds that exhibit potent insecticidal activity, suggesting that these pesticides may have evolved as a defence mechanism against insects and other herbivores. Spinosad, acts upon nAChRs (Millar and Denholm, 2007), by disrupting binding of acetylcholine in nicotinic acetylcholine receptors at the postsynaptic cell (Salgado, 1997). This insecticide causes excitation of the insect nervous system, leading to involuntary muscle contractions, prostration with tremors, and finally paralysis. These effects are consistent with the activation of nicotine acetylcholine receptors by a mechanism that is clearly novel and unique among known insect pest control products. Furthermore, it also has effects on GABA receptor function that may contribute further to its insect activity. The reason for extraordinary margins of selectivity between certain insects, mammals, and other non-target organisms is not fully understood.(Tran,2007). In target organisms, the compound is 5 to 10 time more effective when ingested than when used as a contact insecticide. Thus, the chemical has little effect on sucking insects.

Spinosad is considered to be a "fast-acting" insecticide. Death occurs in 1 to 2 days and there appears to be no recovery. Generally, treatment provides 7 to 14 days of control. Although Spinosad is thought to have a novel mode of activity, resistance management is perceived to be an essential practice in perpetuating the long-term effectiveness of this insecticide.Spinosad has demonstrated control activity against insect pests of the orders Lepidoptera, Coleoptera and Thysanoptera.It can be used on a variety of agricultural and ornamental crops to control various pests (e.g. noctuid caterpillars, leaf miners, thrips) (Orme and Kegley (2006). Beside that, Van Leeuwen et al. (2005) improved that application of Spinosad to the roots of tomato plants in rock wool,obtained excellent control of spider mites. Apparently, Spinosad has systemic properties and quantities as low as $1 \mathrm{mg} /$ plant could protect tomato plants from Tetranychus urticae Koch infestation.

The present study was carried out at Plant Protection Research Institute, Dakahlia Branch, in 
order to study toxicological effects of Spinosyns against adult females of $A$. gossypii Glover and T. urticae and the fourth instar larvae of Spodoptera littoralis (Boisd.) under laboratory conditions with referring to explanation of toxic effects of these compounds depending on the programme AUTODOCK to generate docking predictions for their effects on vpltage gated potassium channels.

\section{MATERIALS AND METHODS}

\section{1- Tested Spinosyns:}

Both tested compounds are provided from Dow AgroSciences, Indianapolis, USA.

\subsection{Spinosad $24 \% \mathrm{SC}$}

1.1.1. Common name: Tracer, Success

1.1.2. Formula : $\mathrm{C}_{41} \mathrm{H}_{65} \mathrm{NO}_{10}$ (spinosyn $\left.\mathrm{A}\right)+$ $\mathrm{C}_{42} \mathrm{H}_{67} \mathrm{NO}_{10}$ (spinosyn D).

1.1.3. Activity: Insecticides (spinosyn insecticides).

\subsection{Spinetoram $12 \% \mathrm{SC}$}

1.2.1. Common names: RADIANT, DELEGATE

1.2.2. Formula: $\mathrm{C}_{42} \mathrm{H}_{69} \mathrm{NO}_{10}+\mathrm{C}_{43} \mathrm{H}_{69} \mathrm{NO}_{10}$

1.2.3. Activity: Insecticides (spinosyn insecticides).

\section{Tested pests}

\subsection{Cotton Aphid, Aphis gossypii}

Laboratory strain was maintained under conditions of $25 \pm 2^{\circ} \mathrm{C}$ and $65 \pm 5 \% \mathrm{RH}$ on castor bean leaves according to methods described by Norman and Sutton (1967).

\subsection{Two-spotted spider mite, Tetranychus urticae}

Laboratory strain was maintained under conditions of $25 \pm 2^{\circ} \mathrm{C}$ and $60 \pm 5 \% \mathrm{RH}$ on castor bean leaves according to the methods described by Dittrich (1962).

\subsection{Cotton leafworm, Spodoptera littorallis}

Laboratory strain was maintained under conditions of $25 \pm 1^{\circ} \mathrm{C}$ and $70 \pm 5 \% \mathrm{RH}$ on castor bean leaves according to the methods described by El-Defrawi et al. (1964).

\section{Assessment of Spinosyns activity:}

Serial concentrations of Spinosad and Spinetoram in water were prepared.Leaf dip technique was used as described by Dittrich(1962) in case of T. urticae and according to Praveen and Regupathy (2004) and Aydin et al. (2005) for A. gossypyii and $S$. littoralis, respectively. Mortality percentages were measured after $24 \mathrm{~h}$ and they were corrected by Abott's formula (1925) then subjected to probit analysis by Finney's method (1971).

\section{Histological studies:}

Treated pests with their $\mathrm{LC}_{50 \text { 's }}$ of Spinetoram were used in histological studies in the nAch receptors, which were done according to Day (1948) with some modifications especially in case of T. urticae.

\section{RESULTS AND DISCUSSION}

\section{1-Bioassay of Spinosyns}

Spinosyns were tested for their toxic effects against adult females of $A$. gossypii, T. urticae and the fourth instar larvae of $S$. littoralis.

$\mathrm{LC}_{50}$ 's and their corresponding slopes were tabulated in table (1). Comparing the relative toxicities of the used Spinosyns against mentioned pests. It showed that Spinetoram was the most toxic compound generally. Spinosad $\mathrm{LC}_{50}$ 's recorded 30.417, 25.982 and $5.379 \mathrm{ppm}$ for A. gossypii, $T$. urticae and $S$. littoralis, respectively. In the same trend, $\mathrm{LC}_{90}$ 's which recorded $73.369,40.012$ and $9.349 \mathrm{ppm}$ for the tested pests, respectively. On the other hand, Spinetoram improved its efficacy against all tested pests more than Spinosad.Spinetoram $\mathrm{LC}_{50 \text { 's }}$ and $\mathrm{LC}_{90 \text { 's }}$ recorded $(0.596,0.370$ and 1.742 ppm) and (5.977, $4.839 \& 6.936 \mathrm{ppm})$, respectively of the same arrangement of pests. These data showed that Spinosad had a distinct effect on chewing-mouth parts insects, $S$. littoralis, while Spinetoram had its distinct effect on piercing sucking pests, A. gossypii and T. urticae. According to toxicity index , A. gossypii, T. urticae and $S$. littoralis were affected by Spinosad $\mathrm{LC}_{50}$ 's and $\mathrm{LC}_{90}$ 's $(1.959,1.424$ and $32.385 \%)$, respectively, as Spinetoram, the most potent compound at $\mathrm{LC}_{50}$ \& $\mathrm{LC}_{90 ' \mathrm{~s}}$. On basis of slope values, Spinosad had the steepest toxicity line (slopes $=2.044,2.457$ and 2.319), whereas Spinetoram had the flattest ones (slope $=1.881,1.735 \& 1.903)$, respectively of the tested pests.

Table (1): Efficiency of Spinosyns against adult females of Tetranychus urticae and Aphis gossypii and the fourth instar larvae of Spodoptera littoralis.

\begin{tabular}{|c|c|c|c|c|c|c|c|}
\hline \multirow{2}{*}{$\begin{array}{l}\text { The } \\
\text { Pest }\end{array}$} & \multirow{2}{*}{$\begin{array}{c}\text { Tested } \\
\text { Compound }\end{array}$} & \multirow[t]{2}{*}{$\begin{array}{l}\mathrm{LC} 50 \\
\text { (ppm) }\end{array}$} & \multirow{2}{*}{$\begin{array}{c}\mathrm{LC} 90 \\
(\mathrm{ppm})\end{array}$} & \multirow[t]{2}{*}{ Slope } & & & \multirow[t]{2}{*}{$\begin{array}{l}\mathrm{LC}_{90} / \\
\mathrm{LC}_{50}\end{array}$} \\
\hline & & & & & $\mathrm{LC}_{50}$ & $\mathrm{LC}_{90}$ & \\
\hline \multirow{2}{*}{$\begin{array}{l}\text { A. } \\
\text { gossypii }\end{array}$} & & & & & 1.959 & 46 & 2.42 \\
\hline & & & & 1.881 & 100 & 100 & 1007 \\
\hline \multirow{2}{*}{$\begin{array}{l}T . \\
\text { urticae }\end{array}$} & & & & 2.457 & 1.42 & 12.094 & 1.54 \\
\hline & & & & & 100 & 100 & \\
\hline \multirow{2}{*}{$\begin{array}{l}\text { S. } \\
\text { littoralis }\end{array}$} & & & & 27 & & & 172 \\
\hline & & & & 903 & 100 & 100 & .982 \\
\hline
\end{tabular}


Considering the $\mathrm{LC}_{90} / \mathrm{LC}_{50}$ ratio, Spinetoram $\mathrm{LC}_{50}$ of $T$. urticae, which showed the highest slope of toxicity line recorded the lowest ratio (1.54), whereas Spinosad $\mathrm{LC}_{50}$ of the same pest, had the lowest slope, recorded the highest ratio (13.078).

In this respect, these results are in agreement with researches detected that Spinosad must be ingested by the insect; therefore it has little effect on piercing-sucking insects and non-target predatory insects. Spinosad is relatively fast acting. The insect dies within 1 to 2 days after ingesting the active ingredient and there appears to be no recovery (Anonymous, 2003).

Results were in agreement with Aydin et al. (2005), who detected that $\mathrm{LC}_{50}$ values for field and susceptible strains of $S$. littoralis were 43.691 and $10.037 \mathrm{ppm}$, respectively. When $\mathrm{LC}_{50}$ values and 95\% confidence intervals were compared with a susceptible laboratory reference strain, the field strain was approximately 4.4-fold less sensitive than the susceptible strain. They suggested that Spinosad was potentially important in the control of $S$. littoralis.

In the same trend, Hatem (2006) mentioned that $\mathrm{LC}_{50}$ of Spinosad against $S$. littoralis was $1.38 \mu \mathrm{g} / \mathrm{ml}$. Likewise, at 2.98 ppm (95\% C.L.: 2.25-4.06 ppm), the $\mathrm{LC}_{50}$ value calculated for second instar S. frugiperda (J. E. Smith) exposed to Spinosad using the diet surface contamination technique was virtually identical to the $3 \mathrm{ppm}$ value (95\% C.L.: 1.10-6.60) for Spinosyn A reported for S. frugiperda larvae of unspecified instar exposed by drench (Bret et al., 1997). In the same way, the $\mathrm{LC}_{50}$ calculated for Spinosad used in diet surface contamination bioassays were performed with $S$. frugiperda, was $2.98 \mathrm{ppm}$ (range of 95\% C.L.: 2.25-4.06 ppm) (Méndez et al, 2002).

Villanueva and Walgenbach (2006) tested the effect of Spinosad under laboratory conditions against T. urticae and Panonychus ulmi (Koch) females by leaf dipping technique. Using 25, 55, 121 and $266 \mathrm{ppm}$ they found that significantly fewer $T$. urticae offspring completed development on any Spinosad rates $(<15 \%)$ compared with the control $(>85 \%)$, whereas Spinosad exhibited no significant effects on P. ulmi development; 72.5 and $83.1 \%$ of P. ulmi completed development on apple (Malus pumila) leaf disks treated with $75 \mathrm{ppm}$ Spinosad and the control, respectively. T. urticae adult females placed on Spinosad-treated disks had significantly higher mortality and lower oviposition rates compared with the water control; no significant mortality effects were observed until 3 days after placing adults on leaf disks. These results indicated that Spinosad had significant acaricidal effects against $T$. urticae but not $P$. ulmi.

Brévault et al. (2009) evaluated the initial activity of Spinosad against the cotton bollworms Helicoverpa armigera (Hübner), Diparopsis watersi (Rotschild), and Earias spp. Spinosad was effective at controlling larvae of first and second instars but not larvae of third to fifth instars. All tested insecticides effectively controlled Earias larvae (8798\% mortality). Regarding D. watersi, Spinosad caused $95 \%$ mortality. In rainy conditions, Spinosad persistence was 8.9 days.

On the other hand, Cote (2001) reported that Azadirachtin, Pyridaben and Spinosad did not suppress T. urticae population at low rates. Mortality from Hexythiazox and Spinosad residues was not significantly greater than the control. In addition, Lechuge et al. (2004) mentioned that Spinosad caused mortality at $200 \mathrm{ppm}$ against $S$. littoralis and Helicoverpa armigera.

The next step of the present study exploited of proposed mechanism of insecticides activities which explained upon the X-ray crystal structures of potassium channels provided insight into how homologous members of the ion channel family were gated.

Comparison of the closed-state KcsA (Streptomyces lividans potassium channel),(Doyle, 1998), with the open-state Mthk (Methanobacterium thermo autotrophicum potassium channel) (Mullaley and Taylor,1994) and KvAP (Jiang et al., 2003) channels showed that gating of the pore was associated with the pore-lining helices (S6 helices in sodium voltage-gated channels) in case of pyrethroids, undergoing bending around a central glycine residue. Glycine was suitable as a gatinghinge as it can adopt a wide range of backbone dihedral angles, conferring flexibility on a polypeptide chain.

The programme AUTODOCK was used to generate docking predictions for the Spinosad and Spinetoram, fig. (1), in the vicinity of two key residues implicated in tetracyclic lactones binding AT cysteine residues in the S3-S4 linker (A359C) and pore (S424C). A $10 \AA$ wide central pore is located near the center of the transmembrane channel where the energy barrier is highest for the transversing ion due to the hydrophobity of the channel wall, (fig. 2). The water-filled cavity and the polar C-terminus of the pore helices ease the 
energetic barrier for the ion. Repulsion by preceding multiple potassium ions is thought to aid the throughput of the ions. The presence of the cavity can be understood intuitively as one of the channel's mechanisms for overcoming the dielectric barrier, or repulsion by the low-dielectric membrane, by keeping the $\mathrm{K}^{+}$ion in a watery, high-dielectric environment (Judge and Bever, 2006).

So, both tested pesticides depending on breaking the hydrophobity of the $\mathrm{K}^{+}$channel wall, espically Spinetoram which have $\mathrm{NH}_{2}$ group. This group goes into watery cavity and the reaction provided 3, 4-Diaminopyridine (fig.4), and works by blocking potassium channel efflux in nerve terminals so that action potential duration is increased. $\mathrm{Ca}^{2+}$ channels can then be open for longer time and allow greater acetylcholine release to stimulate muscle at end plate., while Spinosad reaction provides just 4-Aminopyridine (fig. 3), which is one of the three isomeric amines of pyridine. This explanation pushed us to study histopathological effects of Spinetoram at $\mathrm{nAch}$ receptors as coming.

\section{2-Histological Studies of Spinetoram:}

Spinetoram improved its highly efficacy on the main tested pests. Thus, the present histological studies were concerned with it only. Each pest was treated with its $\mathrm{LC}_{50}$ value of Spinetoram.

Histological defects after treatment with Spinetoram on adult females of $T$. urticae, $A$. gossypii and the fourth instar larvae of $S$. littoralis are shown in fig. (5) .It concentrated on nAch receptors which located at the edges of junctional folds at the neuromuscular junction on the postsynaptic side, (Miyazawa et al., 2003). They were activated by acetylcholine release across the synapse. The diffusion of $\mathrm{Na}^{+}$and $\mathrm{K}^{+}$across the receptor caused depolarization, the end-plate potential, that opened voltage-gated sodium channels, which allowed for firing of the action potential and potentially muscular contraction.

Revealed defectes in A. gossypii showed nAch receptor in fig. (5a). Normal $A$. gossypii had normal neurogalia-schwann cells in their normal shape and size, with normal axoplasm. The neuropile was clear. The neuromuscular gap was shown in normal size and the motor end plates were also normally. In treated A.gossypii, the neurogalia-schwann cells were more than that in the control with more axoplasm. Neuromuscular gap was smaller and the motor end plates were so close. The neuropile was absent. Muscular layer was detached totally because they were targeted especially those located around postsynaptic cells. Fig. (5b) showed the nAch receptor in T. urticae .Normal T. urticae had normal neurogalia-schwann cells with mitochondria and glycogen filaments. Neuromuscular gap was cleared of cytoplasm .Muscular cells normaly clefts with normal structure. In $T$. urticae treated with spinetoram, the clustration of neurogalia- schwann cells occurred with more axoplasm,beside more movement towards the outer sheath of the nerve.Changes were also shown in the muscular cells which their mitochondria were enlarged. Alterations in muscle cells were shown clearly in treated T. urticae by disintegrations of mitochondrial cristae. Fig. (5c) showed the nAch receptor in the fourth instar larvae of $S$. littoralis. Normal $S$. littoralis neurogalia-schwann cells were in their normal shape and size, with normal axoplasm. The neuropile was clear. The neuromuscular gap was shown in normal size and the motor end plates were also normal .In treated $S$. littoralis, the neurogaliaschwann cells were more than that in the control with more axoplasm. Neuromuscular gap was

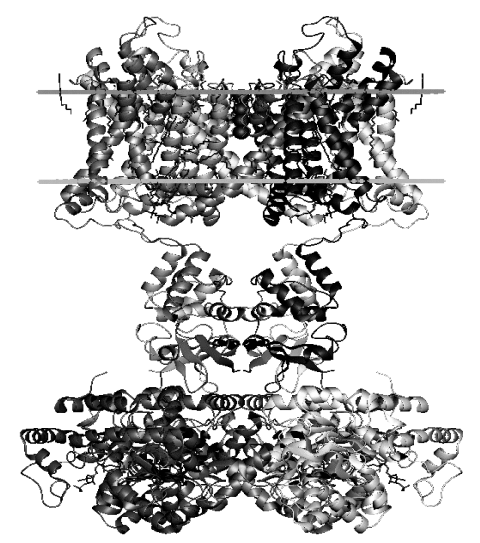

Fig. (2): The tested pest voltage-gated potassium channel model as it appeared in open (upper) or close (lower) cases in response to changes in the transmembrane voltage.
Fig. (1): Docking predictions for the spinosad with $\mathrm{NH}_{2}$ and spinetoram without $\mathrm{NH}_{2}$. 


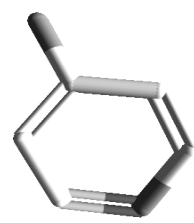

Fig. (3): 4-Aminopyridine, resulted from reaction between helix $\mathrm{K}^{+}$channel membrane and Spinosad.<smiles>Cc1ccccc1C</smiles>

Fig. (4): 3,4-Diaminopyridine, resulted from reaction between helix $\mathrm{K}^{+}$channel membrane and Spineoram.
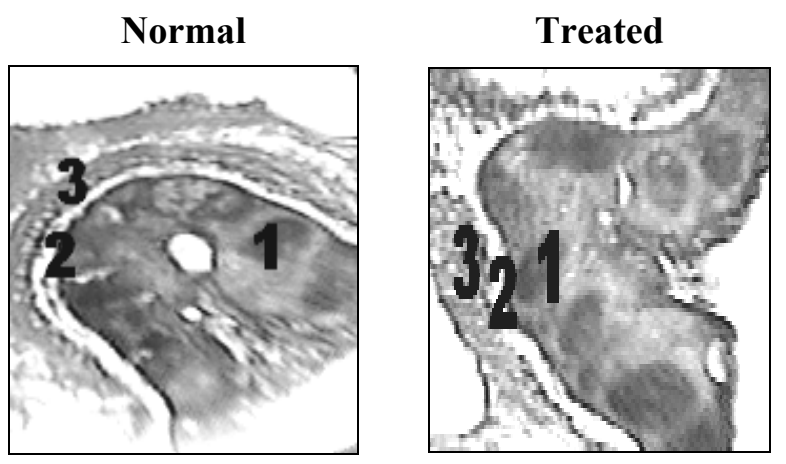

a): A. gossypii

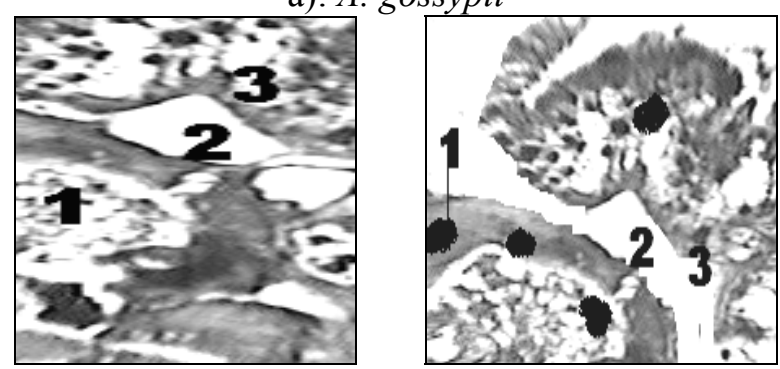

b): T. urticae
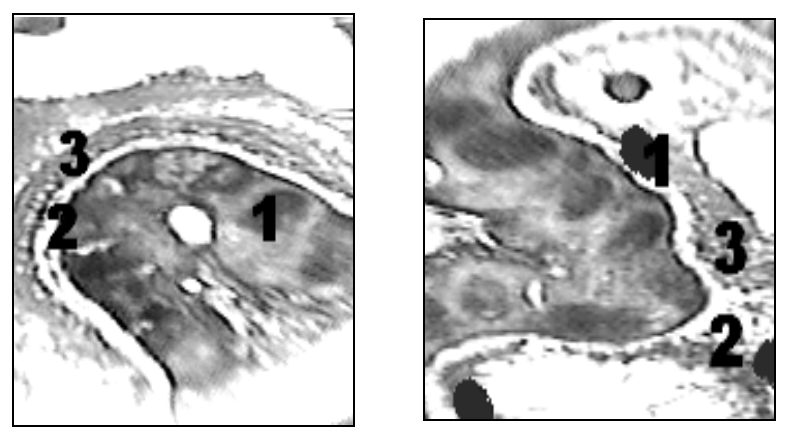

c): S. littoralis

Figure (5): Histological defects after treatment with Spinetoram on adult females of $A$. gossypii and T. urticae and the fourth instar larvae of $S$. littoralis.

Normal: neurogalia-schwann cells with neuropile, 2-neuromuscular gap, 3-Muscular layer

Treated: neurogalia-schwann cells with nearly abscent neuropile, 2-neuromuscular gap, 3- Muscular layer. smaller and the motor end plates were so close. The neuropile was absent. The nuclei of the fat cells were clumped into dense masses in all the fat bodies in the $S$. littoralis larvae, suggesting an affinity of the toxicant with one or more of fat components.

Gained results were in the same way with many studies such as Unwin (2003) reporting that the nicotinic acetylcholine (ACh) receptor was the transmitter-gated ion channel at the nerve/muscle synapse. Electron microscopical experiments on isolated postsynaptic membranes determined the structure of this channel and how the structure changed upon activation. When ACh entered the ligand-binding domain, it initiated rotations of the protein chains on opposite sides of the entrance to the membrane-spanning pore. These rotations were communicated to the pore-lining $\alpha$-helices and open the gate - a constricting hydrophobic girdle at the middle of the membrane by breaking it apart. The movements were small and involve energetically favourable displacements parallel to the membrane plane.

Heathcote (2004) studied the neural basis of the locust flight as an exclusively adult behavior. The coordinated neural pattern underlying this behavior appeared rapidly at the end of postembryonic development. Alternative extreme hypotheses were: (1) the neurons and synapses involved develop concomitant with the behavior, or (2) they were constructed early in development, and were activated at the appropriate time by, for example, the release of inhibition. These hypotheses were evaluated by selecting a synapse that was important in adult flight, and monitoring its physiological features during postembryonic development. The synapse between the forewing Stretch Receptor (SR) and the First Basalar (BA) motor neuron, two uniquely identified neurons, mediated a monosynaptic reflex which operates only in flight.

Leitch et al., (2004) used a polyclonal antibody raised against nicotinic acetylcholine receptor protein from purified locust neuronal membrane to analyse the distribution of antigenic sites within the central nervous system of adult Schistocerca gregaria. Microscopic examination showed that all principal neuropiles in the thoracic ganglia label with the antibody but that the major tracts and commissures did not. Analysis of this pattern of staining in the electron microscope revealed that the receptor was presented on specific synaptic and extrajunctional neuronal membranes in the neuropile. Antigenic sites were also evident on the plasma membranes and within the cytoplasm 
adjacent to Golgi complexes of some neuronal somata, suggesting that these neurones synthesises nicotinic acetylcholine receptors. In addition to neuronal labelling, there was evidence that the receptor was also present on the membranes of three types of glial cells.

\section{REFERENCES}

Abott, W. S. 1925. A method of computing effectiveness of an insecticides.J.Econ.Entomol.18:265-267.

Anonymous. 2003. IPM of Alaska. Biorational insecticide profile :Spinosad (spinosyn).

Aydin, H.; Oktay, M. and Rkan, G. 2005. The efficacy of spinosad on different strains of Spodoptera littoralis (Boisduval) (Lepidoptera: Noctuidae). Turk. J. Biol. 30: 5-9.

Bret, B.; Larson, L.; Schoonover, J.; Sparks, T. and Thompson, G. 1997. Biological properties of Spinosad. Down to Earth. 52: 6-13.

Brévault, T. ; Oumarou, Y.; Achaleke, J.; Vaissayre, M. and Nibouche, S. 2009. Initial activity and persistence of insecticides for the control of bollworms (Lepidoptera: Noctuidae) in cotton crops. Crop Protection. 28(5): 401-406.

Cote, K. 2001. Using selected acaricides to manipulate Tetranychus urticae Koch populations in order to enhance biological control provided by phytoseiid mites. M. Sc. Virginia Tech, Blacksburg, Va. pp. 200.

Day, M. F. 1948. References for an outline of insect histology. Council for Scientific and Industrial Research (Australia). pp.223

Dittrich, V. 1962. A comparative study of toxicological test methods on a population of the two-spotted spider mite, T. urticae. J. Econ. Entomol.55:633-648.

Doyle, D. A. 2004. Structural changes during ion channel gating. Trends Neurosci. 27(6): 298-302.

El-Defrawi, M. E., Tappozada, A.; Mansour, N. and Zeid, M. 1964. Toxicological studies on egyptian cotton leaf worm Prodenia litura (F.)1: susceptibility of different larval instars of Prodenia litura to insecticides. J. Econ. Entomol. 57: 591-593.

Finney, S. J. 1971. Probit analysis. Astatistical treatment of the sigmoid response curve. $7^{\text {th }} \mathrm{Ed}$. Campridge Univ. Press, Cambridge, England.

Hatem, A. 2006. Comparación de los effectos de insecticidas selectivos sobre el desarrollo y reproducción de Spodoptera littoralis (Boisduval) (Lep.:Noctuidae). Thesis Doctoral. Universidad de Córdoba. Córdoba (España).

Heathcote, R. D. 2004. Physiological development of a monosynaptic connection involved in an adult insect behavior. J. Comparat. Neurol. 191(2): 155-166.

Huang, K. X.; Xia, L.; Zhang, Y.; Ding, X. and Zahn, J. A. 2009. Recaent advances in the biochemistry of spinosyns. Appl. Microbiol. Biotechnol. 82(1): 13-23.

Jiang Y, Ruta V, Chen J, Lee A, and MacKinnon, R. 2003. The principle of gating charge movement in a voltage-dependent potassium channel. Nature (Lond) 423: 42-48.

Judge, S. I.; Bever, C. T. 2006. Potassium channel blockers in multiple sclerosis: neuronal $\mathrm{Kv}$ channels and effects of symptomatic treatment. Pharmacol. Ther. 111 (1): 224-59.

Kirst, H. A.; Michel, K. H.; Martin, J. W.; Creemer, L. C.; Chio, E. H.; Yao, R. C.; Nakatsukasa, W. M.; Boeck, L.; Occolowitz, J. L. and Paschal, J. W. 1991. A83543A-D, unique fermentationderived tetracyclic macrolides. Tetrahedron Lett., 32(37): 4839-4842.

Lechuge, A.; Hatem, E. and Ramos, J. 2004. Comparación de la susceptibilidad de larvaes de Spodoptera littoralis y Helicoverpa armigera al Spinosad, un insecticida de origin natural. Bol. San. Veg. Palgas, 300: 573-580.

Leitch,B.; Branwen , L.; and Burrows, M. 2004. Distribution of acetylcholine receptors in the central nervous system of adult locusts. J. Comparat. Neurol. 334(1): 47-58.

Méndez, W.; Valle, J.; Ibarra, E.; Cisneros, J. and Penagos, D. 2002. Spinosad and nucleopolyhedrovirus mixtures for control of Spodoptera frugiperda (Lepidoptera: Noctuidae) in maize. Biological Control. 25: 195-206.

Mertz, F. P. and Yao, R. C. 1990. Saccharopolyspora spinosa sp. nov. isolated from soil collected in a sugar mill rum still. Int. J. Syst. Bacteriol., 40: 34-39.

Millar, N. S. and Denholm, I. 2007. Nicotinic acetylcholine receptors: targets for commercially important insecticides. Invertebrate Neuroscience. 7(1): 53-66

Miyazawa A, Fujiyoshi Y, Unwin, N. 2003. Structure and gating mechanism of the acetylcholine receptor pore. Nature, 423 (6943): 949-55

Mullaley, A.and Taylor, R. 1994. Conformational properties of pyrethroids. J. Comput.-Aided Mol. 8: 135 - 141.

Norman, P. A. and Sutton, R. A. 1967. Host plants for laboratory rearing of melon aphid. J. Econ. Entomol. 60: 1205-1207.

Orme, S. and Kegley, S. 2006. PAN Pesticide Database, Pesticide Action Network, North 
America (San Francisco, CA. 2006), http:www.pesticideinfo.org.

Praveen P. M. and Regupathy, A. 2004. Generating baseline data for insecticide resistance monitoring in cotton aphid, Aphis gossypii Glover Resist. Pest Mgmt., 12 (2): 17-28.

Salgado, V. L. 1997. The modes of action of spinosad and other insect control products. Down to Earth 52(2):35-43.

Tran, M. 2007. Spinetoram,a new Spinosyn compound.Special report.2007. Dow Agro Sciences LOC, Indianapolis, Indiana.

Unwin, N. 2003. Structure and action of the nicotinic acetylcholine receptor explored by electron microscopy. 2003, FEBS letters, 555(1): 91-95.

Van Leeuwen, T.; Dermauw, W.; Van de Veire, M. and Tirry, L. (2005). Systemic use of spinosad to control the two-spotted spider mite (Acari: Tetranychidae) on tomatoes grown in rockwool. Exp. Appl. Acarol. 37(2): 93-105.

Villanueva, R. T. and Walgenbach, J. F. (2006). Acaricidal properties of spinosad against Tetranychus urticae and Panonychus ulmi (Acari: Tetranychidae). J. Econ. Entomol. 99(3): 843-849. 